\title{
FORMULATION AND IN VITRO IN VIVO EVALUATION OF BOSENTAN PELLETS FOR PROLONGED DRUG RELEASE
}

\author{
NARENDER KARRA ${ }^{1 *}$, NARAYANA RAJU ${ }^{2}{ }^{2}$, SIVAKUMAR R ${ }^{2}$ \\ ${ }^{1}$ Department of Pharmaceutics, Malla Reddy Institute of Pharmaceutical Sciences, Maisammaguda, Secunderabad, Telangana, India. \\ ${ }^{2}$ Department of Pharmaceutical Chemistry, Geethanjali College of Pharmacy, Cheeryal, Telangana, India. \\ E-mail: narenderreddy.karra@gmail.com \\ Received: 08 June 2018, Revised and Accepted: 21 June 2018
}

ABSTRACT

Objective: The objective of this study was to develop extended release (ER) pellets of Bosentan, an endothelin receptor antagonist using fluid bed processor (coating).

Method: The ER drug pellets of Bosentan were prepared using fluid bed coating. These drug-loaded pellets were further coated with ethyl cellulose of two viscosity grades and Eudragit as rate controlling polymers individual and in combination, hypromellose as pore former and binder, acetyl tributyl citrate as plasticizer, and magnesium stearate as anti-adhering agent.

Results: The drug release was extended up to $24 \mathrm{~h}$, and the drug release was mainly depends on the polymer type and polymer proportion. In vivo study of Bosentan, ER pellets were performed in healthy rabbits (New Zealand, White) of either sex weighing (3.0-3.3 kg) and were divided into two separate groups, each group consisting of 6 animals. Maximum plasma concentration $\left(\mathrm{C}_{\max }\right)$, maximum time $\left(\mathrm{T}_{\max }\right)$, area under the curve $\left(\mathrm{AUC} \mathrm{C}_{0-\mathrm{t}}\right)$, elimination rate constant $\left(\mathrm{K}_{\mathrm{el}}\right)$, and half-life $\left(\mathrm{T}_{1 / 2}\right)$ were studied for optimized formulation. Formulation was releasing the drug for a prolonged period of time.

Conclusion: By the above results, it was observed that the prepared pellets could release the drug for an extended period when compared with the conventional dosage form of Bosentan, optimized formulation was shown longer half-life and $\mathrm{C}_{\max }$ indicates its acceptability. Finally, ER pellets of Bosentan were prepared for the treatment of pulmonary artery hypertension by fluid bed processor.

Keywords: Bosentan, Pellets, EC, Eudragits, Prolonged release pellets.

(C) 2018 The Authors. Published by Innovare Academic Sciences Pvt Ltd. This is an open access article under the CC BY license (http://creativecommons. org/licenses/by/4. 0/) DOI: http://dx.doi.org/10.22159/ajpcr.2018.v11i8.27833

\section{INTRODUCTION}

It is estimated that $40 \%$ or more of active substances being identified through combinatorial screening programs are poorly soluble in water [1]. Poor solubility is not only a problem for the formulation development and clinical testing; it is also an obstacle at the beginning when screening new compounds for pharmacological activity. There is a definite need for smart technological formulation approaches to make such poorly soluble drugs bioavailable [2].

Multi-particulate dosage forms (MPDFs) are receiving immense attention as alternative drug delivery systems for oral drug delivery even though single-unit dosage forms have been widely used for decades [3]. MPDFs offer advantages over conventional dosage forms such as (1) predictable, reproducible and short gastric residence time, (2) less inter and intrasubject variability, and (3) improve bioavailability [4,5]. Pelletization is often called a size enlargement process that involves the production of agglomerates relatively with a narrow size range of $0.5 \mathrm{~mm}-2 \mathrm{~mm}[6,7]$ and they are called pellets. Pellets have free-flowing properties and low porosity of about $10 \%$. Since their multi-particulate nature offers many important pharmacological as well as technological advantages over conventional single unit solid dosage form, these formulations are preferred over other solid dosage forms [8]. In the past two decades, pellets have established their position for many reasons [9].

Pellets offer greater flexibility in pharmaceutical solid dosage form design and development. They flow freely and pack easily without significant difficulties, resulting in uniform and reproducible fill weight of capsules and tablets. Ethylcellulose, a hydrophobic polymer which has more controlled release properties and used in the preparation of many dosage forms. Therefore, in this study, it was used to extend the drug release $[10,11]$.

Extendable drug delivery systems come under controlled drug delivery systems, which are used to extend the release rate of drugs over an extended rate of period $[12,13]$.

Bosentan is an endothelin receptor antagonist (ERAs). Patients with PAH have elevated levels of endothelin, a potent blood vessel constrictor, in their plasma and lung tissue. Bosentan blocks the binding of its receptors, thereby negating endothelins deleterious effects. Its oral bioavailability is approximately $50 \%$, and food does not affect its absorption. It is having a terminal elimination half-life of $5 \mathrm{~h} \mathrm{[14].}$

From the above information on Bosentan, it is essential to formulate extended release (ER) dosage forms with least side effects as it has the oral bioavailability $50 \%$, it is essential to increase bioavailability, and the half-life also need to be prolonged to improve the patient compliance by reducing the frequency of administration. This drug is indicated for the pulmonary artery hypertension; a chronic condition requires prolonged drug release.

\section{MATERIALS AND METHODS}

\section{Materials}

Bosentan was obtained as a free sample from Aurobindo Pharma Ltd, Hyderabad. MCC spheres were obtained from Aurobindo Pharma, HPMC E5 was obtained from Colorcon Asia, Ethyl Cellulose, Eudragit of different grades, and Magnesium stearate were obtained from Tini 
Pharma Pvt., Ltd. All other chemicals and reagents used in the study were of analytical grade.

\section{Preparation methods}

\section{Method for estimation of Bosentan}

High-performance liquid chromatography (HPLC) method for the estimation of Bosentan was used for routine analysis of Bosentan in its formulations such as drug content and in vitro dissolution and drug content uniformity.

\section{Preparation of mobile phase}

The mobile phase was prepared using phosphate buffer of pH 7.4 and Acetonitrile at a ratio of 40:60 (Buffer:acetonitrile)

\section{Preparation of stock solution}

Accurately weighed $100 \mathrm{mg}$ of Bosentan was transferred into $100 \mathrm{ml}$ volumetric flask and dissolved in few $\mathrm{ml}$ of mobile phase and then further diluted and make up the volume up to $100 \mathrm{ml}$ with using same mobile phase.

\section{Preparation of standard solutions}

From the above stock solution, standard concentrations of 50, 100, and $150 \mu \mathrm{g} / \mathrm{ml}$ solutions and the samples were filtered through $0.45 \mu$ Millipore filter. The samples were loaded into the Shimadzu HPLC System model No 1020 CHT with autosampler. A standard calibration curve was plotted using the standard peak areas versus concentration.

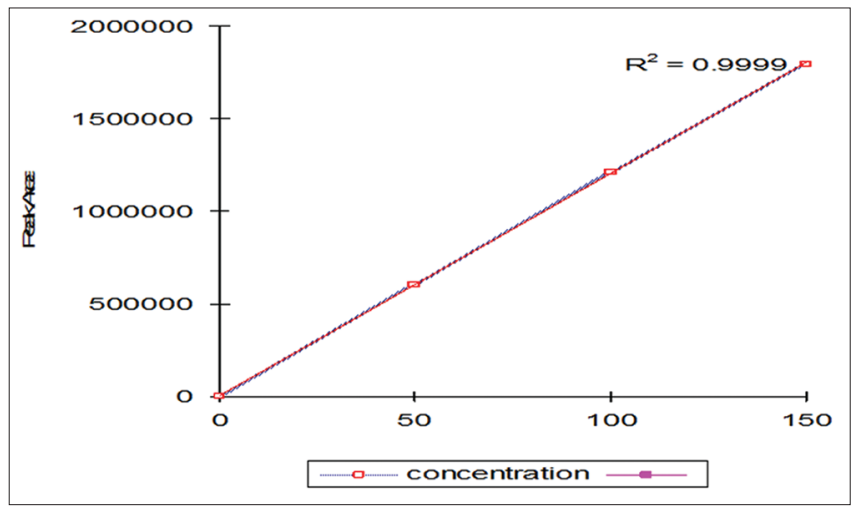

Fig. 1: Calibration curve of Bosentan in $0.1 \mathrm{~N}$ hydrochloric acid

Table 1: Peak areas of the Bosentan

\begin{tabular}{lc}
\hline Concentration in $\mu \mathbf{g} / \mathbf{m l}$ & Peak area \\
\hline 50 & 615768 \\
100 & 1232177 \\
150 & 1868566 \\
\hline
\end{tabular}

The column used for the analysis is C-18, inspire, $250 \times 4.6 \times 5 \mu$. The detector wavelength was $265 \mathrm{~nm}$. The peak is of Bosentan and was showed in Table 1, and the calibration curve as shown in Fig. 1.

\section{Drug loading on MCC spheres}

MCC spheres were loaded into the fluid bed processor [15-19], the process parameters were adjusted as per the machine setting. The MCC spheres then preheated to the required temperature as per the set parameters. The drug solution was then sprayed on to the spheres using the peristaltic pump. The process parameters were monitored and then adjusted as per the pellets fluidization and weight gain. The prepared pellets were then dried for $12 \mathrm{~h}$ in a hot air oven to remove the complete moisture.

ER coating solution on drug-loaded pellets was prepared using ethyl cellulose and Eudragit. The solvent used in polymer solution was IPA and MDC. Tributyl citrate was used as plasticizer. Initially, ethylcellulose was added to the IPA and MDC 30:70 RATIO. The solution was then stirred for $30 \mathrm{~min}$ then plasticizer was added to it finally talc and magnesium stearate was added and stirred to get the uniform dispersion. The prepared solution was sprayed on to the drug-loaded pellets.

\section{ER coating on drug-loaded pellets: $[20,21]$}

The drug-loaded pellets were loaded into fluid bed processor. The pellets were preheated up to $45^{\circ} \mathrm{C}$. The inlet and exhaust temperatures were set as per the requirement. The polymer solution was then sprayed on to the drug-loaded pellets. The different ratio or percent of the polymer ethyl cellulose alone and in combination with Eudragits were prepared and loaded on to the pellets. The pellets were then dried in a tray dryer overnight for complete evaporation of the solvent. The formula for ER coating solution of different polymers individually and in combination on drug-loaded pellets was shown in Table 2.

\section{Evaluation of ER pellets}

\section{In vitro dissolution studies}

Dissolution studies for each prepared formulation were performed in a calibrated dissolution test apparatus (LABINDIA), equipped with paddles (USP apparatus II method). $900 \mathrm{ml}$ of $0.1 \mathrm{~N}$ hydrochloric acid solution was used as a dissolution medium. The paddles were operated at $50 \mathrm{rpm}$, and the temperature was maintained at $37 \pm 0.5^{\circ} \mathrm{C}$ throughout the experiment. Dissolution samples were withdrawn from the apparatus at regular intervals, i.e., 1, 2, 3...up to $24 \mathrm{~h}$ and replaced with equal volume of dissolution medium to maintain the sink condition throughout the experiment. Samples were withdrawn at various time intervals were suitably diluted with same dissolution medium, and the amount of drug released was estimated by chromatographically at $272 \mathrm{~nm}$

\section{In vivo study design}

In vivo study of Bosentan, ER pellets were performed in healthy rabbits (New Zealand, White) of either sex weighing (3.0-3.3 kg) were divided

Table 2: ER coating on drug-loaded pellets using EC N 10, N50, and Eudragit

\begin{tabular}{|c|c|c|c|c|c|c|c|c|c|c|c|c|c|c|}
\hline \multirow[t]{2}{*}{ Ingredients } & \multicolumn{14}{|c|}{ ER coating on MCC Spheres Mg/Unit } \\
\hline & CB1 $^{\#}$ & CB2 & CB3 & CB4 & CB5 & CB6 & CB7 & CB8 & CB9 & CB10 & CB11 & CB12 & CB13 & CB14 \\
\hline Drug loaded pellets & 128 & 128 & 128 & 128 & 128 & 128 & 128 & 128 & 128 & 128 & 128 & 128 & 128 & 128 \\
\hline Ethyl cellulose $10 \mathrm{cps}$ & 15 & 20 & 25 & 30 & $* *$ & $* *$ & $* *$ & $* *$ & $* *$ & $* *$ & $* *$ & $* *$ & 30 & 30 \\
\hline Ethyl cellulose $50 \mathrm{cps}$ & $* *$ & $* *$ & $* *$ & $* *$ & 5 & 10 & 15 & 20 & 10 & 10 & 10 & 10 & $* *$ & $* *$ \\
\hline Eudragit NE30D & $* *$ & $* *$ & $* *$ & $* *$ & $* *$ & $* *$ & $* *$ & $* *$ & 2.5 & 5 & 7.5 & 10 & 7.5 & 10 \\
\hline Talc & 5 & 5 & 5 & 5 & 5 & 5 & 5 & 5 & 5 & 5 & 5 & 5 & 5 & 5 \\
\hline HPMC E 5 & 6 & 6 & 6 & 6 & 6 & 6 & 6 & 6 & 6 & 6 & 6 & 6 & 6 & 6 \\
\hline Tributyl citrate & 2 & 2 & 2 & 4 & 4 & 4 & 6 & 6 & 6 & 8 & 8 & 8 & 8 & 8 \\
\hline IPA & Qs & Qs & Qs & Qs & Qs & Qs & Qs & Qs & Qs & Qs & Qs & Qs & Qs & Qs \\
\hline MDC & Qs & Qs & Qs & Qs & Qs & Qs & Qs & Qs & $* *$ & $* *$ & $* *$ & $* *$ & $* *$ & $* *$ \\
\hline Water & & & & & & & & & Qs & Qs & Qs & Qs & Qs & Qs \\
\hline Th. Weight & 156 & 161 & 166 & 168 & 146 & 151 & 158 & 163 & 157.5 & 162 & 164.5 & 167 & 184.5 & 187 \\
\hline
\end{tabular}

$\mathrm{CB}^{\#}$ indicates coated Bosentan pellets. ER: Extended-release 


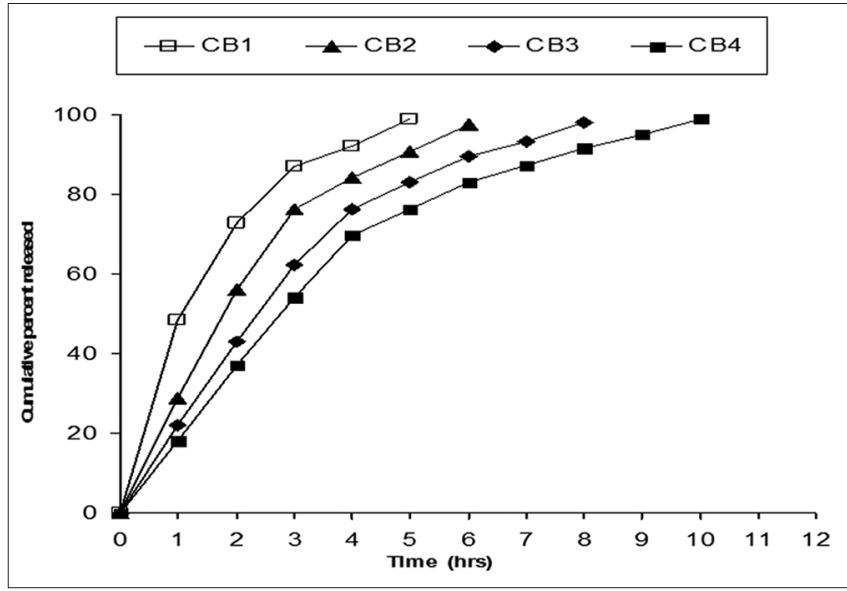

Fig. 2: In vitro drug release profile of formulation CB1-CB4 made with EC N10

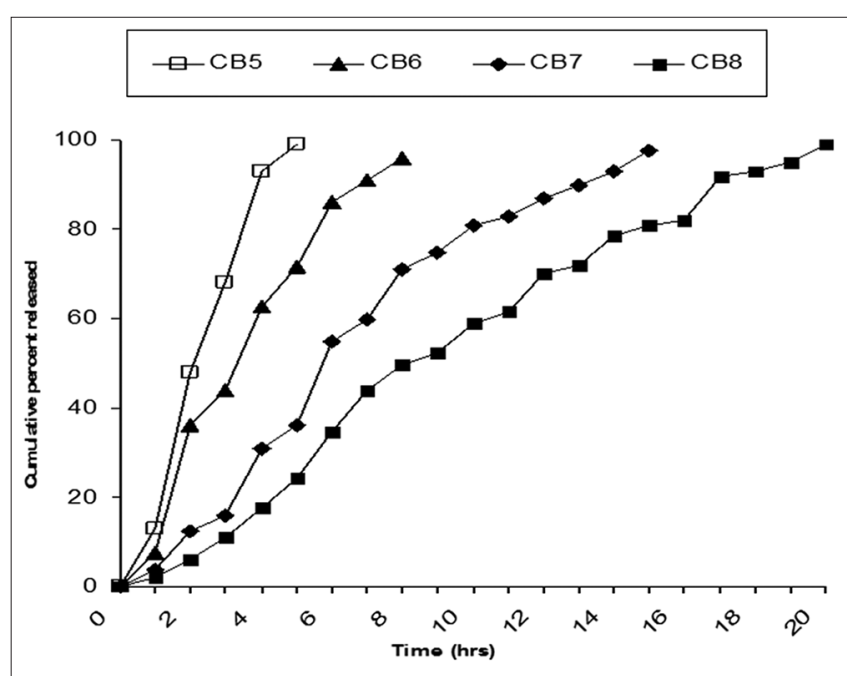

Fig. 3: In vitro drug release profile of formulation CB5-CB8 made with EC N50

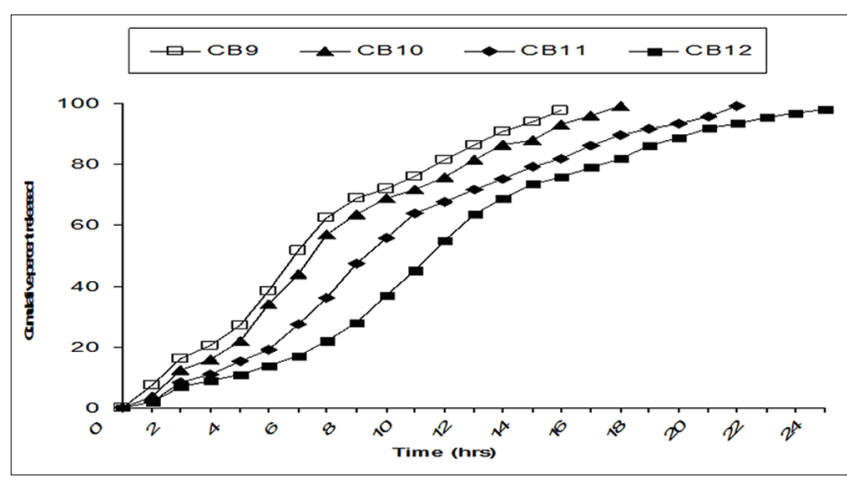

Fig. 4: In vitro drug release profile of formulation CB9-CB12 made with EC N50: Eudragit NE30D

into two separate groups, each group consisting of 6 animals. The first group received conventional beads of Bosentan $(80 \mathrm{mg})$ and the second group received the microbeads of Bosentan contain $80 \mathrm{mg}$ of Bosentan. The beads were put behind the tongue to avoid biting by rabbit. Food was withdrawn from the rabbits before $12 \mathrm{~h}$ of drug administration and until $24 \mathrm{~h}$ post dosing. All rabbits have free access to water during the study period. The Institute Animal Ethical Committee approved the

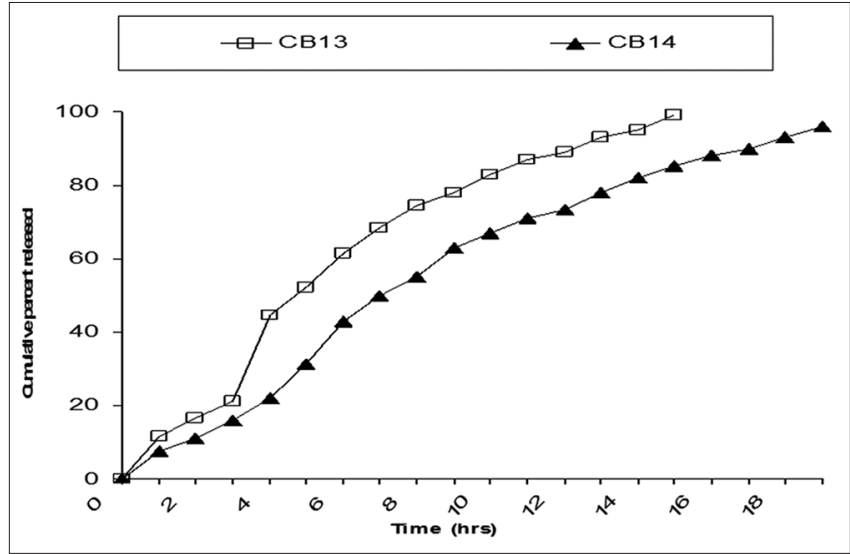

Fig. 5: In vitro drug release profile of formulations CB13-CB14 made with EC N10: Eudragit NE30D

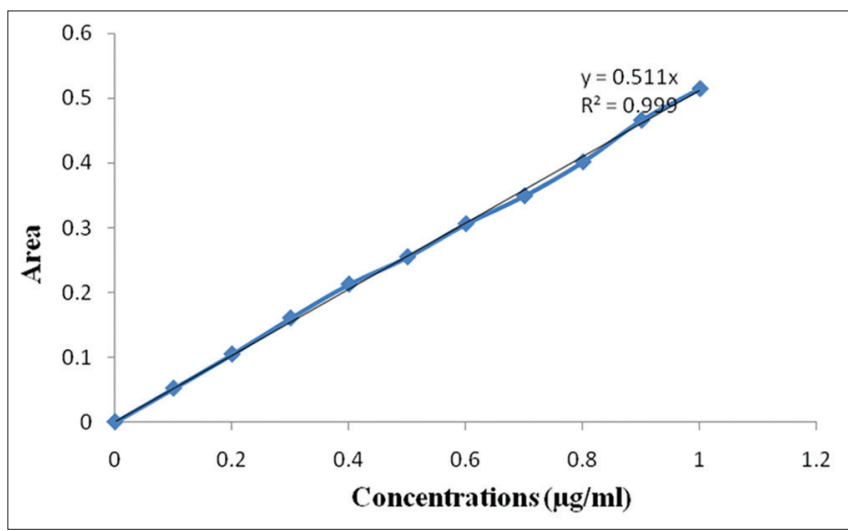

Fig. 6: Standard calibration curve of Bosentan in rabbit plasma

Table 3: Standard calibration curve of Bosentan in rabbit plasma

\begin{tabular}{ll}
\hline Conc. $(\mu \mathrm{g} / \mathrm{ml})$ & Peak Area ratios of Bosentan $(\mathrm{S} / \mathbf{I S})$ \\
\hline 0 & 0 \\
0.1 & 0.052007 \\
0.2 & 0.104633 \\
0.3 & 0.160475 \\
0.4 & 0.212688 \\
0.5 & 0.254922 \\
0.6 & 0.306102 \\
0.7 & 0.349369 \\
0.8 & 0.401659 \\
0.9 & 0.466127 \\
1 & 0.514828 \\
\hline
\end{tabular}

study protocol. PROTOCOL NO: 012/MRIPS/CPCSEA-IAEC/HYD/2018.

\section{Standard calibration curve}

Preparation of standard solution $10 \mathrm{mg}$ of Bosentan monohydrate was weighed accurately and transferred into $100 \mathrm{ml}$ volumetric flask. Ensured to dissolve the un-dissolved portions of drug by sonicating and final volume was made with mobile phase. Aliquot of $1 \mathrm{ml}$ was taken and transferred into a $10 \mathrm{ml}$ clean and dry volumetric flask, and it was diluted up to the mark with the same diluent $(10 \mu \mathrm{g} / \mathrm{ml})$. From this, $1 \mathrm{ml}$ was taken and further diluted to $10 \mathrm{ml}$ to get a concentration of $1 \mu \mathrm{g} / \mathrm{ml}$.

\section{Blood sampling}

Blood samples were collected at $0.25,0.5,1.0,1.5,2,3,4,6,8,12$, and $24 \mathrm{~h}$ from marginal ear vein. Blood collected was centrifuged at $2000-$ 
Table 4: Pharmacokinetic data of Bosentan 80 mg immediate-release tablets (R)

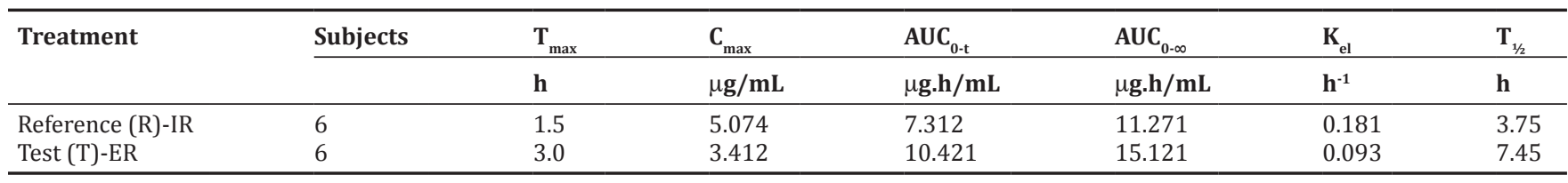

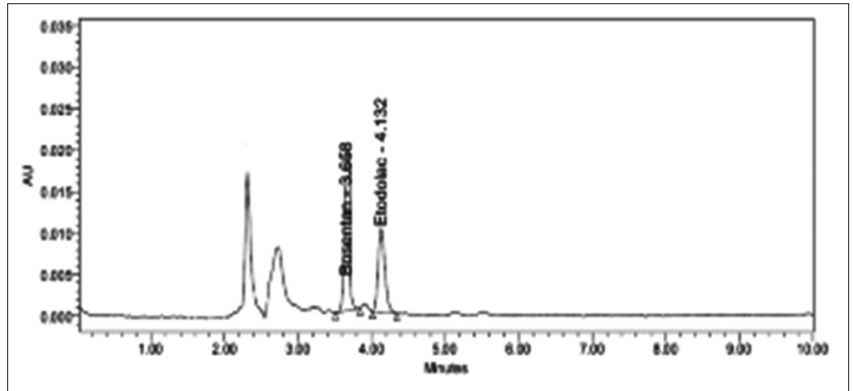

Fig. 7: High-performance liquid chromatography chromatogram of Bosentan and Internal standard rabbit plasma

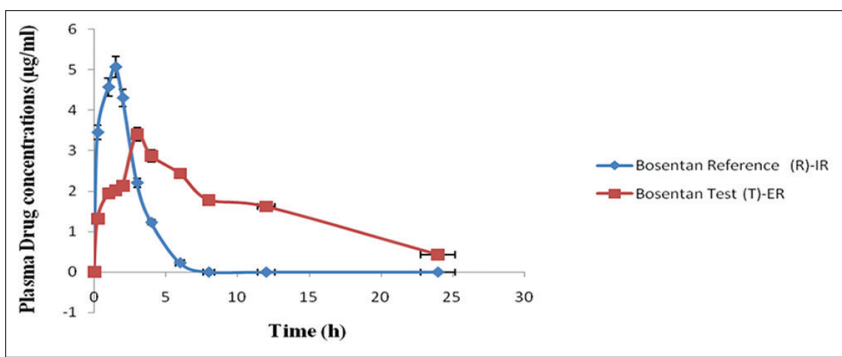

Fig. 8: Comparative plasma profiles of Bosentan $80 \mathrm{mg}$ conventional formulation (R) with Bosentan 80 mg ER Pellets formulation (T)

$3000 \mathrm{rpm}$ for 10 min (Remi Equipment, Mumbai, India). The plasma samples were stored at refrigerator condition $\left(-20^{\circ} \mathrm{C}\right)$ until analysis. Safety was evaluated by monitoring adverse events and vital signs and through physical examination.

\section{Analytical method and instrumentation}

Analyses were performed on a Shimadzu Scientific Instruments (Kyoto, Japan) liquid chromatographic system composed of a LC-10AT pump, a SPD-10A UV detector, and an ODS C-18 column $4.6 \mathrm{~mm} \times 250 \mathrm{~mm}$ ) oven $25 \mu \mathrm{l}$ Hamilton injection syringe.

\section{Chromatographic conditions}

The mobile phase consisted of acetonitrile and phosphate buffer ( $\mathrm{pH} 4.6)$ in 80:20 ratio. Before analysis, the mobile phase was filtered through a $0.22 \mu \mathrm{m}$ filter (Sartorius, USA), and then degassed ultrasonically for 15 min. The analysis was conducted at $25^{\circ} \mathrm{C}$, flow-rate of $1.0 \mathrm{ml} / \mathrm{min}$ and detection wavelength at $273 \mathrm{~nm}$.

\section{Extraction procedure of Bosentan}

Extraction of drug from plasma of New Zealand rabbits $250 \mu \mathrm{l}$ of plasma containing varying amount of Bosentan monohydrate was taken into a Teflon lined cap centrifuging tube followed by addition of $50 \mu \mathrm{l} \mathrm{of} 2 \mu \mathrm{g} / 0.5 \mathrm{ml}$ of etodolac [internal standard (I/S)] and $2 \mathrm{ml}$ of acetonitrile. The mixture was vortexed for $2 \mathrm{~min}$ and centrifuged at $3300 \mathrm{rpm}$ speed until organic layer was separated. Organic layer was collected and filtered through $0.2 \mu \mathrm{m}$ membrane filter. $20 \mu \mathrm{l}$ of filtrate was injected into the analytical column, and the eluents were observed at $273 \mathrm{~nm}$. The concentrations in the range of $0.1-5 \mu \mathrm{g} / 0.5 \mathrm{ml}$ of plasma were prepared. The experiment was repeated for 5 times for all the concentrations.

\section{RESULTS AND DISCUSSION}

In vitro dissolution studies were performed for all prepared pellets to find out the drug release, drug release mechanisms and also to know the effect of concentration and proportion of polymers used for extending the drug release from the core of the formulations. Among all the formulations, CB12 formulation was selected as best or optimized formulation based on the drug release and its physical properties. The formulation CB12 was extended the drug release up to $24 \mathrm{~h}$, and it was prepared with Ethylcellulose N 50 (ECN50) and Eudragit polymer. Results were showed in Figs. 2-5.

\section{Standard calibration curve of Bosentan in rabbit plasma}

Linearity was observed within the range of $0.1-1 \mu \mathrm{g} / \mathrm{ml}$ with correlation coefficient of 0.999 showed in Fig. 6 and the values were shown in Table 3. The retention time of Bosentan was found at $3.648 \mathrm{~min}$ and the retention time of the etodolac (I/S) was found at $4.132 \mathrm{~min}$ (Fig. 7).

\section{Pharmacokinetic assessment}

All the pharmacokinetic results were showed in Table 4. The plasma kinetic data were assessed with KINETIKA 5.0 software. Fig. 8 shows the mean comparative data plot of the mean plasma concentration of the Bosentan in both test (ER formulation) and reference (conventional formulation). The mean peak plasma concentration of test (T) formulation $\mathrm{C}_{\max } 3.412 \mu \mathrm{g} / \mathrm{ml}$ was gradually reached in $3.0 \mathrm{~h}$. In case of conventional reference formulation (R), the $\mathrm{C}_{\text {max }}$ was $5.074 \mu \mathrm{g} / \mathrm{ml}$ which was reached in $1.5 \mathrm{~h}$. The concentration maximum of the test formulation (T) was lower when compared with reference (R) formulation. The increased $\mathrm{T}_{\max }$ was clearly indicates the drugs availiability for the longer duration. Tables show the kinetic data of Bosentan conventional formulation (R) and ER formulations (T), respectively.

The reference (R) formulation was absorbed rapidly, the $T_{\text {max }}$ reached in about $1.5 \mathrm{~h}$. After reaching the $\mathrm{T}_{\text {max }}$, the drug starts rapid elimination and the concentration gradually reduced. In case of test (T) formulation, the $\mathrm{T}_{\max }$ achieved gradually, and the drug availability was long time.

The $\mathrm{AUC}_{0 . t}$ of the reference (R) was found to be $7.312 \mu \mathrm{g} \mathrm{min} / \mathrm{ml}$, the increase in $\mathrm{AUC}_{0-\mathrm{t}}$ of around $10.421 \mu \mathrm{g} \mathrm{min} / \mathrm{ml}$ was observed in the test (T) formulation, and this clearly indicates the drug availability for long period of time.

Decrease in elimination rate constant $\left(\mathrm{K}_{\mathrm{e}}\right)$ from $0.181 \mathrm{~h}^{-1}$ (Reference) (R) to $0.093 \mathrm{~h}^{-1}$ (Test) indicates the lower release rate of drug in the body.

The half-life $\left(\mathrm{T}_{1 / 2}\right)$ of the reference (R) and test (T) formulations were $3.75 \mathrm{~h}$ and $7.45 \mathrm{~h}$, respectively, which were significantly different. Thus, the prolonged $\mathrm{T}_{1 / 2}$ is another indication on the in vivo performance of the Bosentan ER beads.

The overall $\mathrm{C}_{\text {max' }}, \mathrm{T}_{\text {max }}, \mathrm{AUC}_{0-\mathrm{r}^{\prime}} \mathrm{K}_{\mathrm{el}}$, and $\mathrm{T}_{1 / 2}$ were completely different between both test and reference formulation. Therefore, the prepared formulation was releasing the drug for a prolonged period of time.

\section{CONCLUSION}

A fluid bed coating method was successfully applied to make Bosentan prolonged-release pellets. Drug solution was loaded into the MCC spheres, and then the drug-loaded spheres were coated with ECN50, and Eudragit NE30D in different proportions of polymers were used 
among those formulation CB12 with 1:1 proportion of ECN50 and Eudragit was shown better drug release. The in vitro release profiles indicated that the release of Bosentan from the pellets exhibited a controlled release behavior. In vivo studies were conducted in New Zealand rabbits. Based on the results of in vivo study, the overall $\mathrm{C}_{\text {max }^{\prime}}$ $\mathrm{T}_{\text {max }}, \mathrm{AUC}_{0-\mathrm{t}}, \mathrm{K}_{\mathrm{el}}$, and $\mathrm{T}_{1 / 2}$ were completely different between both test and reference formulation. Therefore, the ready formulation was releasing the drug for a prolonged period. Finally, the present work demonstrates the feasibility of controlled delivery of Bosentan utilizing MCC-based pellets.

\section{CONFLICTS OF INTEREST}

No conflicts of interest.

\section{AUTHOR'S CONTRIBUTION}

We declare that this work was done by the authors named in this article and all liabilities pertaining to claims relating to the content of this article will be borne by the authors

Mr. Narender Karra collected the data, analyzed the data, all the laboratory work performed, and wrote the introduction, discussion, and the material and method part.

Dr.P. Narayana Raju, supervisor of this study helped in selection of the topic, procuring chemicals, drugs from different laboratories, in the preparation of manuscript, designing and conducting of this study. Dr.R siva kumar, cosupervisor of this study, helped me a lot in drafting the manuscript and proofreading.

\section{ACKNOWLEDGMENT}

The authors are thankful our guide P. Narayana Raju and coguide R. Siva Kumar for their support to complete our research work.

The authors are thankful to the management and principle of Malla Reddy Institute of Pharmaceutical Sciences for providing all facilities for this research work.

\section{REFERENCES}

1. Lipinski C. Poor aqueous solubility-an industry wide problem in drug discovery. Am Pharm Rev 2002;5:82-5

2. Katteboinaa S, Chandrasekhar PV, Balaji S. Drug nanocrystals: A novel formulation approach for poorly soluble drugs. Int J PharmTech Res 2009; 1:682-94

3. Prasad MB, Vidyadhara S, Trilochani P. Development and evaluation of diltiazem hydrochloride controlled-release pellets by fluid bed coating process. J Pharm Technol Res 2013;4:101-7.
4. Jyothi BJ, Doniparthy J. Multiparticulate drug delivery systems using natural polymers as release retardant materials. Int J Pharm Pharm Sci 2014;6:61-5.

5. Baramade MK, Patwekar SL. Controlled release approach to novel multiparticulate drug delivery systems. Int J Pharm Pharm Sci 2012;4:757-63.

6. Gajdos B. Rotary granulators-evaluation of process technology for pellet production using factorial design. Drugs Made Ger 1984;27:10-6.

7. Kristensen $\mathrm{HG}$, Schaefer T, Granulation. A review of pharmaceutical wet granulation. Drug Dev Ind Pharm 1987;13:803-72.

8. Ghebre-Sellassie I. Pellets: A General overview in Pharmaceutical Pelletization Technology. Vol. 37. New York, USA: Marcel Dekker, Inc.; 1989. p. 1-13.

9. Ghebre SI, Gordon R, Fawzi MB, Nesbitt RU. Evaluation of a highspeed pelletization process and equipment. Drug Dev Ind Pharm 1985; $11: 1523-41$.

10. Moorthy KS, Kumar KP. Studies on formulation and evaluation of ethylcellulose based extended release metformin hydrochloride matrix tablets. Asian J Pharm Clin Res 2016;9:309-15.

11. Rao KR, Senapathi P, Das MK. Formulation and in vitro evaluation of ethyl cellulose microspheres containing zidovudine. J Microcapsul 2005;22:863-76.

12. Kumar KP, Bhowmik D, Dutta A, Paswan S, Deb L. Recent trends in scope and opportunities of control release oral drug delivery systems. Crit Rev Pharm Sci 2012;1:20-33.

13. Arafat M. Approaches to achieve an oral controlled release drug delivery system using polymers: A recent review. Int J Pharm Pharm Sci 2015;7:16-21.

14. Holm P, Liska J, Clozel Ml. The endothelin antagonist bosentan: hemodynamic effects during normoxia and hypoxic pulmonary hypertension in pigs. J Thorac Cardiovasc Surg 1996;11:890-7.

15. Maryandele J, O’Neil, Smith A, Patricia E, Heckelman, Susan B. The Merck Index. 30 ${ }^{\text {th }}$ ed. White House Station, NJ: Merck Research Laboratories; 2001.

16. Sweetman SC. Matrindale-the Complete Drug Reference. $34^{\text {th }}$ ed. London: Pharmaceutical Press; 2002.

17. Langtry HD, Benfield P. Zolpidem: A review of its pharmacodynamic and pharmacokinetic properties and therapeutic potential drugs. Pub Med 1990;40:291-313

18. Thoma K, Ziegler I. The PH independent release of fenoldopam from pellets with insoluble film coats. Eur J Pharm Biopharm 1998;46:105-13

19. Shivakumar HN, desai BG, Sarasija S. Design and evaluation of $\mathrm{pH}$ sensitive multiparticulate systems for chronotherapeutic delivery of diltiazem hydrochloride. Ind J Pharm Sci 2006;68:781-7.

20. Gangurde HH, Chordiya MA, Tamizharasi S, Sivakumar T. Statistical optimization of mesalamine coated pellets for possible ileo-ceacal targeting. Mahidol Univ J Pharm Sci 2013;40:25-44.

21. Tubati VP, Murthy TE, Rao AS. Formulation development and statistical optimization of ivabradine hydrochloride floating pulsatile pellets by fluidized bed coating technique. Asian J Pharm Clin Res 2016;9:159-66. 